\title{
Commentary: Total artificial heart in the pediatric population...proceed with caution
}

\author{
Katsuhide Maeda, MD, PhD
}

\author{
From the Department of Cardiothoracic Surgery, Stanford University School of Medicine, Stanford, Calif. \\ Disclosures: Author has nothing to disclose with regard to commercial support. \\ Received for publication Aug 18, 2019; revisions received Aug 18, 2019; accepted for publication Aug 19, 2019; \\ available ahead of print Oct 11, 2019. \\ Address for reprints: Katsuhide Maeda, MD, PhD, Department of Cardiothoracic Surgery, Stanford University, \\ 300 Pasteur Drive, Stanford, CA 94305 (E-mail: kmaeda@stanford.edu). \\ J Thorac Cardiovasc Surg 2020;159:e233-4 \\ 0022-5223/\$36.00 \\ Copyright $(2019$ by The American Association for Thoracic Surgery \\ https://doi.org/10.1016/j.jtcvs.2019.08.067
}

In this issue of The Journal of Thoracic and Cardiovascular Surgery, Alaeddine and colleagues ${ }^{1}$ reported a successful implantation of a total artificial heart (50-cc Syncardia temporary Total Artificial Heart) with subsequent heart transplantation after 69 days of support without significant complications in a 10 -year-old child. Needless to say, this was a technically challenging case, but it is worth mentioning that the authors proceeded very deliberately and thoughtfully to achieve a successful result. This report raises 3 key points.

First, the authors initially used temporary mechanical support as a means to stabilize the patient before committing to any durable device. Temporary circulatory devices have advantages over durable support and have been used more often in the current era. ${ }^{2}$ Temporary devices are relatively easier to implant via either a percutaneous approach or less invasive surgical techniques and the management of these devices is also flexible and versatile. Temporary devices can be a better alternative tool to facilitate end organ recovery compared with traditional extracorporeal membrane oxygenation support, provided that pulmonary function is reasonable. In addition, temporary support can serve as a useful test to see if mechanical support works on the sick patient.

Second, the device selection was carefully, and logically made, and total artificial heart was selected instead of any of the available ventricular assist devices. Device support in a patient with incessant ventricular arrhythmia is very challenging. Three options can be considered: (1) left ventricular assist device with automatic implantable cardioverter-defibrillator, (2) biventricular assist device, or (3) total artificial heart. The choice will vary somewhat with institutional experience and device availability. Biventricular support using HeartWare devices in pediatric populations has been reported with success. ${ }^{3}$ However, in this case, the patient had aneurysmal tissue in the ventricle, and it is probably best to avoid placement of sutures into friable ventricular tissue, because this can lead to intramyocardial dissection.

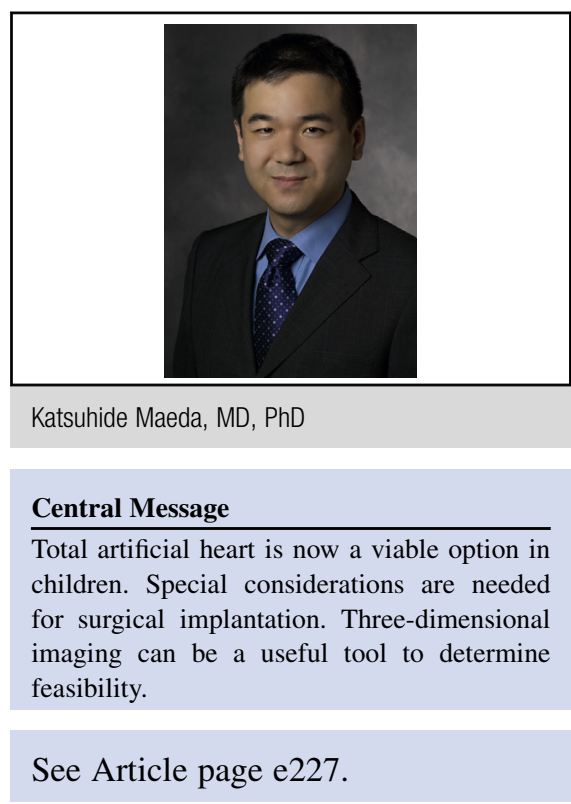

Third, to examine the feasibility of total artificial heart, a virtual fit test was performed using 3-D reconstructed magnetic resonance imaging. Three-dimensional fit test is becoming recently more popular and useful. For surgeons, it is a great tool to get a better image and plan details of implantation, as well as to test the feasibility of the procedure. One question about this test is how to validate and determine feasibility. When a large device is implanted in a pediatric patient, the pericardium is often incised at the level of the diaphragm. As a result, the device sits inside the pleural space rather than the pericardial space, which could potentially cause chronic lung compression, and might not be well tolerated for some patients. In terms of the available space, it is possible to create more space by dissecting the diaphragm and creating a pocket in the abdomen. These factors should be considered in interpreting the results of any fit test.

The availability of the 50-cc Syncardia has expanded the range of patients in whom total artificial heart support can be considered. The authors demonstrate a useful application of this device in a pediatric patient. More experience in this area is awaited.

\section{References}

1. Alaeddine M, Ploutz M, Arabia FA, Velez D. Implantation of total artificial heart in a 10-year-old after support with a temporary perventricular assist device. J Thorac Cardiovasc Surg. 2020;159:e227-9. 
2. Yarlagadda VV, Maeda K, Zhang Y, Chen S, Dykes JC, Gowen MA, et al. Temporary circulatory support in U.S. children awaiting heart transplantation. J Am Coll Cardiol. 2017;70:2250-60.
3. Stein ML, Yeh J, Reinhartz O, Rosenthal DN, Kaufman BD, Almond CS, et al HeartWare HVAD for biventricular support in children and adolescents: the Stan ford experience. ASAIO J. 2016;62:e46-51. 